\title{
Improved image quality in GRAPPA-accelerated coronary MRA using an outer volume suppressing 2D-T 2 -Prep
}

\author{
Andrew J Coristine ${ }^{1,2^{*}}$, Jerome Yerly ${ }^{1,2}$, Matthias Stuber ${ }^{1,2}$ \\ From 18th Annual SCMR Scientific Sessions \\ Nice, France. 4-7 February 2015
}

\section{Background}

Two-dimensional (2D) spatially selective radiofrequency (RF) pulses may be used to excite a restricted volume of tissue. By incorporating a "pencil beam" 2D pulse into a $\mathrm{T}_{2}$-Prep module, one may create a " $2 \mathrm{D}$ - $\mathrm{T}_{2}$-Prep" that combines $\mathrm{T}_{2}$-weighting with outer volume suppression. This may be of particular benefit to parallel imaging techniques, where artefacts typically originate from residual foldover signal. By suppressing signal from outside the targeted region of interest (ROI), image quality may thus improve. We present numerical simulations, phantom validation, and in vivo MRA of the right coronary artery to test this hypothesis.

\section{Methods}

The first RF pulse of an adiabatic $\mathrm{T}_{2}$-Prep was replaced with a jinc pulse and spiral gradients. This excites a cylindrical volume. Meanwhile, the final RF pulse remains non-selective; it thus restores the cylinder of $\mathrm{T}_{2}$-prepared magnetization, but also rotates outer magnetization into the transverse plane, where it is spoiled. This " $2 \mathrm{D}-\mathrm{T}_{2}-$ Prep", and its conventional counterpart, were used prior to normal and GRAPPA-accelerated MRI.

First, a numerical phantom, based on real image data (see below), was used to simulate acceleration factors of $\mathrm{R}=1 . .6$ with random coil noise. Through repeated simulations, per pixel maps of SNR, noise, and G-factor were predicted for both $\mathrm{T}_{2}$-Preps.

Next, the actual phantom, with compartments doped to mimic blood, myocardium, and fat, was scanned 50 times for each acceleration and $\mathrm{T}_{2}$-Prep $(50 \times 6 \times 2=600$

'Department of Radiology, University Hospital (CHUV) / University of Lausanne (UNIL), Lausanne, Switzerland

Full list of author information is available at the end of the article total scans), on a $1.5 \mathrm{~T}$ Siemens Aera using a gated, 2D gradient echo, 16 channel chest coil, FoV 384x384 (matrix $384 \times 384$ ), $4.0 \mathrm{~mm}$ slices, $\mathrm{TE} \mathrm{T}_{2}$-Prep $=40 \mathrm{~ms}$, RF angle $20^{\circ}$, and $\mathrm{TE} / \mathrm{TR} / \mathrm{T}_{\mathrm{acq}}=3.4 / 8.7 / 69 \mathrm{~ms}$. For each "tissue", an ROI was chosen and the mean $\mathrm{SNR}_{\text {multi }}$ was calculated.

For in vivo experiments, the RCA was imaged in 10 healthy adults, using accelerations of $\mathrm{R}=1,3$, and 6 . Parameters were as above, though a volume-targeted $3 \mathrm{D}$ sequence was used with $1.5 \mathrm{~mm}$ reconstructed slices, $24 \mathrm{~mm}$ volume thickness, water-selective RF excitation pulses of $20^{\circ}$, and TE $/ \mathrm{TR} / \mathrm{T}_{\mathrm{acq}}=5.2 / 11.6 / 93.0 \mathrm{~ms}$. Both $\mathrm{T}_{2}$-Preps were compared using Soap-Bubble vessel sharpness measurements for each acceleration, and the $\%$ differences were calculated.

\section{Results}

In simulations, the $2 \mathrm{D}-\mathrm{T}_{2}$-Prep signficantly improved SNR for accelerated imaging, peaking at a value of $R=4$. Phantoms also predicted a peak improvement at $\mathrm{R}=4$ (Figure 1, chart). This corresponds to the degree of outer volume suppression of the $2 \mathrm{D}-\mathrm{T}_{2}$-Prep, specifically the reduction of excited tissue in the phase encoding (i. e. accelerated) direction. For in vivo images of the RCA (Figure 2), vessel sharpness improved by a greater $\%$ for higher acceleration factors, demonstrating that the 2D$\mathrm{T}_{2}$-Prep especially benefits accelerated coronary MRA.

\section{Conclusions}

Suppressing outer volume signal with a $2 \mathrm{D}-\mathrm{T}_{2}$-Prep improves image quality particularly well in GRAPPAaccelerated acquisitions in simulations, phantoms, and volunteers, demonstrating that it should be considered when performing accelerated coronary MRA. 


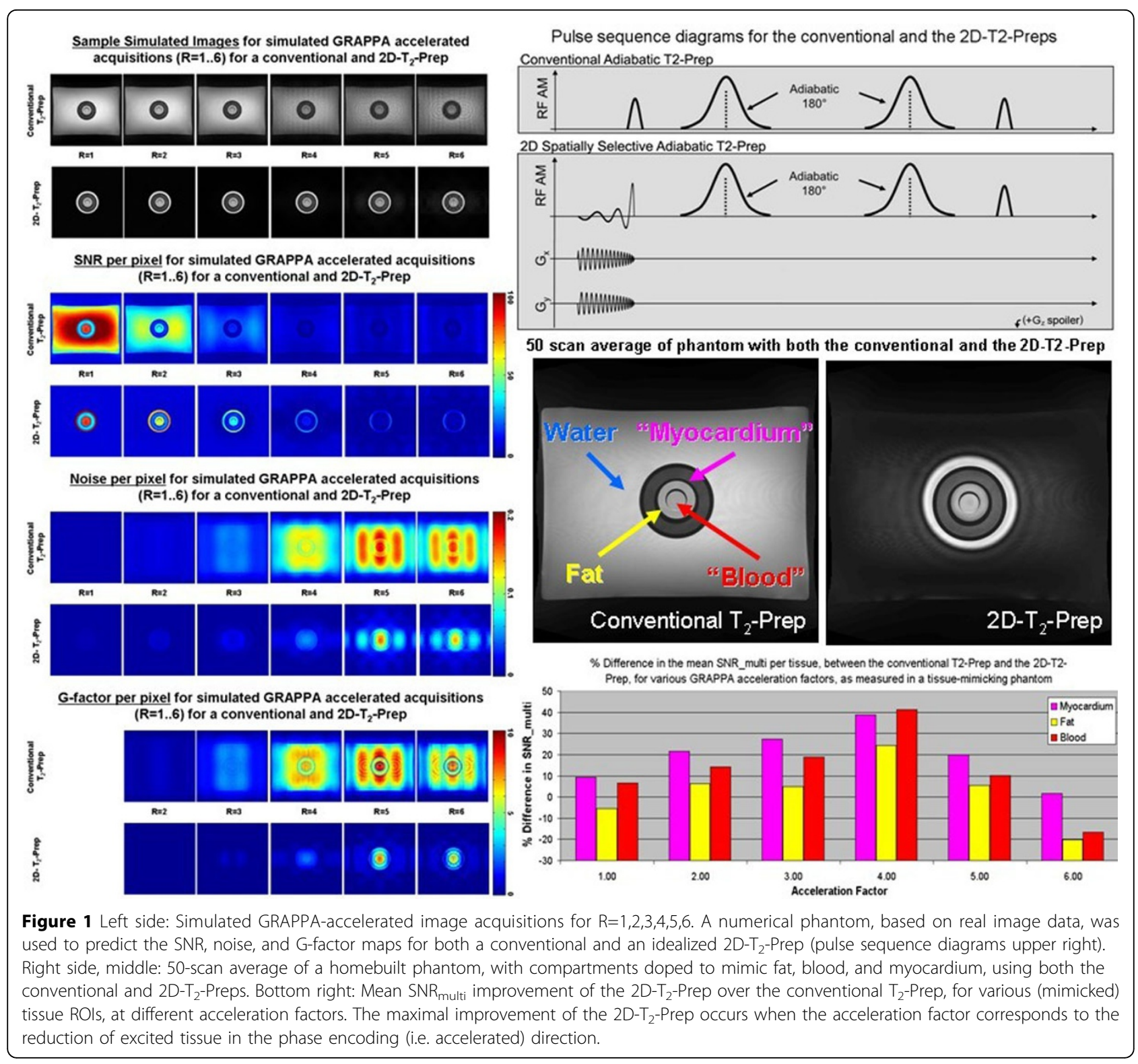

\section{Funding}

This work is supported in part by the grant 320030143923 of the Swiss National Science Foundation.

\section{Authors' details}

'Department of Radiology, University Hospital (CHUV) / University of Lausanne (UNIL), Lausanne, Switzerland. ${ }^{2}$ CardioVascular Magnetic Resonance (CVMR), Centre for Biomedical Imaging (CIBM), Lausanne, Switzerland.

Published: 3 February 2015

doi:10.1186/1532-429X-17-S1-P382

Cite this article as: Coristine et al:. Improved image quality in GRAPPAaccelerated coronary MRA using an outer volume suppressing $2 \mathrm{D}-\mathrm{T}_{2^{-}}$ Prep. Journal of Cardiovascular Magnetic Resonance 2015 17(Suppl 1):P382.
Submit your next manuscript to BioMed Central and take full advantage of:

- Convenient online submission

- Thorough peer review

- No space constraints or color figure charges

- Immediate publication on acceptance

- Inclusion in PubMed, CAS, Scopus and Google Scholar

- Research which is freely available for redistribution 


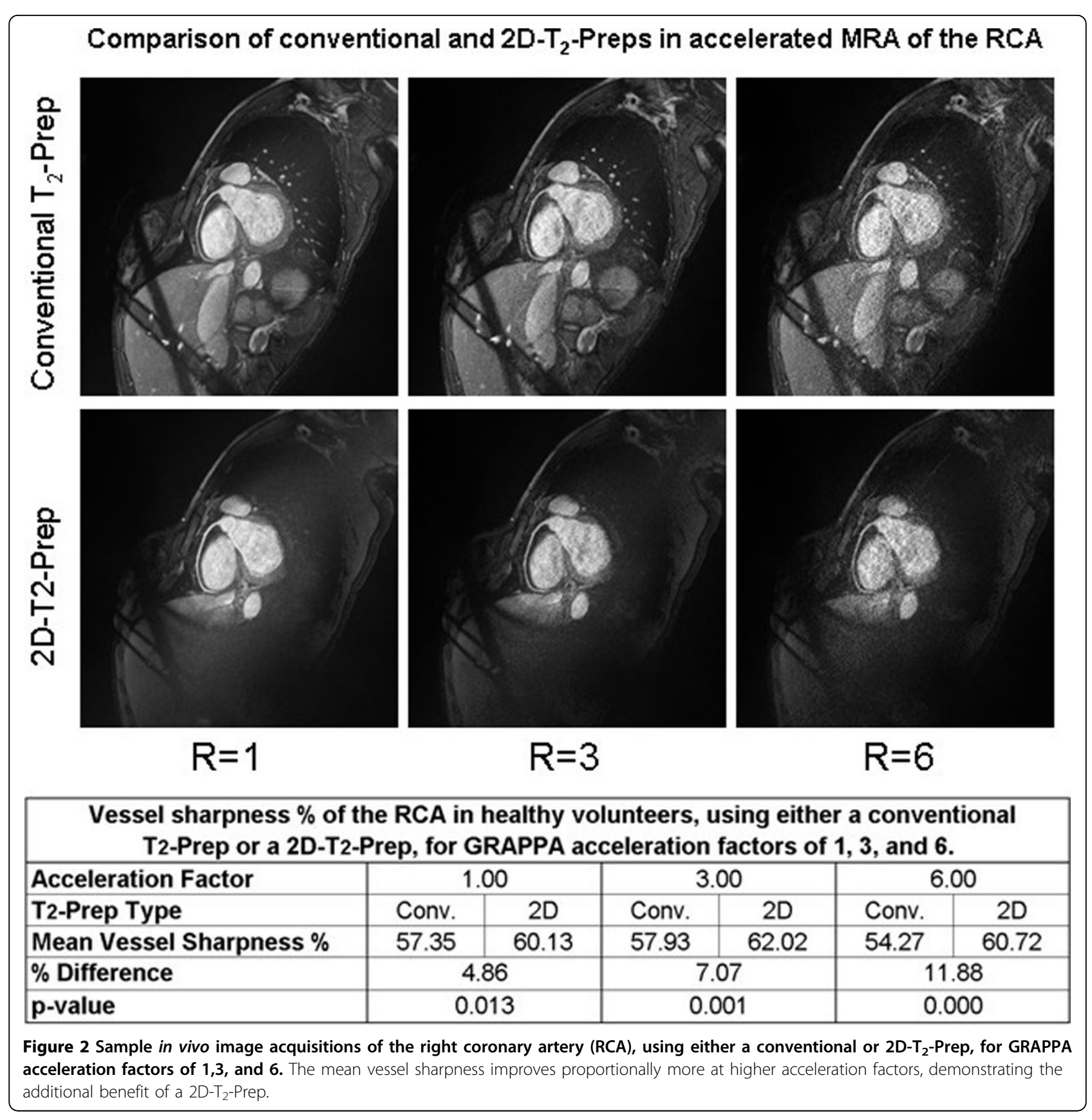

